\title{
Reduction of Current Harmonic Distortion in Three-Phase Grid-Connected Photovoltaic Inverters via Resonant Current Control
}

\author{
Miguel Castilla, Jaume Miret, Member, IEEE, Antonio Camacho, José Matas, and Luis García de Vicuña
}

\begin{abstract}
The resonant current control has been extensively employed to reduce the current harmonic distortion in a wide range of grid-connected distributed generation applications, including photovoltaic (PV) inverters, wind and water turbines, and fuel-cell inverters. However, the performance of these systems is deteriorated when the utility grid voltage experiences abnormal conditions such as voltage harmonics and imbalances. Several advanced control solutions have been recently introduced to cope with this problem but at the cost of a significant increase in the control computational load. This paper first analyzes the limitations of the standard resonant current control operating under abnormal grid conditions and then introduces a control scheme that improves the current harmonic distortion in such adverse conditions without increasing the computational load of the standard current control. This theoretical contribution is validated by means of selected experimental results from a three-phase PV inverter.
\end{abstract}

Index Terms-Distributed generation (DG), photovoltaic (PV), power quality, three-phase inverter.

\section{INTRODUCTION}

$\mathbf{P}$ HOTOVOLTAIC (PV) power generation is a concept of increasing interest. In recent years, a high number of PV systems with a power capacity up to some megawatts have appeared in the distributed generation (DG) scenario. Usually, these PV systems are connected to the commercial utility grid [1]-[8]. They can also form a microgrid with other DG resources, energy storage systems, and local loads [9]-[11]. Regardless of the output connection, power quality is an essential feature of PV systems. The quality of power is mainly governed by practices and standards on voltage, frequency, and harmonics [12]-[14]. In particular, PV systems should have low current harmonic distortion to assure that no adverse effects are caused to other equipment connected to the utility grid or the microgrid. The common practice is to accept a maximum total harmonic distortion (THD) of 5\% at rated inverter output [12].

The resonant current control has been extensively employed to reduce the current harmonic distortion in a wide range of

Manuscript received March 30, 2011; revised May 31, 2011; accepted August 17, 2011. Date of publication September 12, 2011; date of current version November 22, 2012. This work was supported by the Spanish Ministry of Science and Innovation under Grant ENE2009-13998-C02-01.

The authors are with the Department of Electronic Engineering, Technical University of Catalonia, 08800 Vilanova i la Geltrú, Spain (e-mail: miquel. castilla@upc.edu; jmiret@eel.upc.edu; antonio.camacho.santiago@upc.edu; matasalc@gmail.com; vicuna@eel.upc.edu).

Digital Object Identifier 10.1109/TIE.2011.2167734
DG applications [15]-[21], including PV systems [22]-[24], wind and water turbines [23]-[26], and fuel-cell inverters [27], [28]. Essentially, this control uses a proportional-resonant (PRES) compensator to track the fundamental component of the current reference signal and a resonant harmonic (RESH) compensator to attenuate the most important current harmonics [18], [23]. Satisfactory results are easily achieved with this control since the resonant compensators are capable of tracking sinusoidal references of arbitrary frequency with zero steadystate error [17]. The main problem of the resonant current control is the performance deterioration given by abnormal conditions in the utility grid. In such conditions, grid voltage harmonics and phase imbalances may create current reference signals with nonsinusoidal distorted waveforms. Also, grid voltage interharmonics which often appear in standard variablespeed drive applications produce distorted reference signals. As a result, the current harmonic distortion is increased due to precisely the ability of the resonant current control to accurately track the distorted reference waveforms.

Several advanced control schemes, which are characterized by a high harmonic rejection capability, have been recently introduced to cope with the formulated problem [29]-[34]. In these control schemes, the current references are generated by separately processing the positive and negative sequence components. Sophisticated phase-locked loop (PLL) algorithms are also required to generate good-quality sequence components not affected by voltage harmonics, interharmonics, and imbalances [33], [34]. The inherent drawbacks of these control solutions are an inevitable increase of both control complexity and computational load. As an interesting alternative, high harmonic rejection capability is achieved for single-phase applications in [35] and [36]. In these works, the RESH compensator is connected in series with the PRES compensator instead of the typical parallel configuration of the standard resonant current control [23], [24]. Low current distortion is obtained even during polluted grid conditions with a simple control structure, similar to the standard one.

As a starting point, this paper takes into account the main idea introduced in [35] and [36]. That is, it is possible to devise simple resonant control schemes for the injection of grid current with low distortion. A simple control scheme is proposed here as a good alternative of previous control solutions for voltagesource three-phase PV inverters connected to the utility grid. In the proposed control, PRES and RESH compensators are connected in parallel as opposed to the controllers reported in 


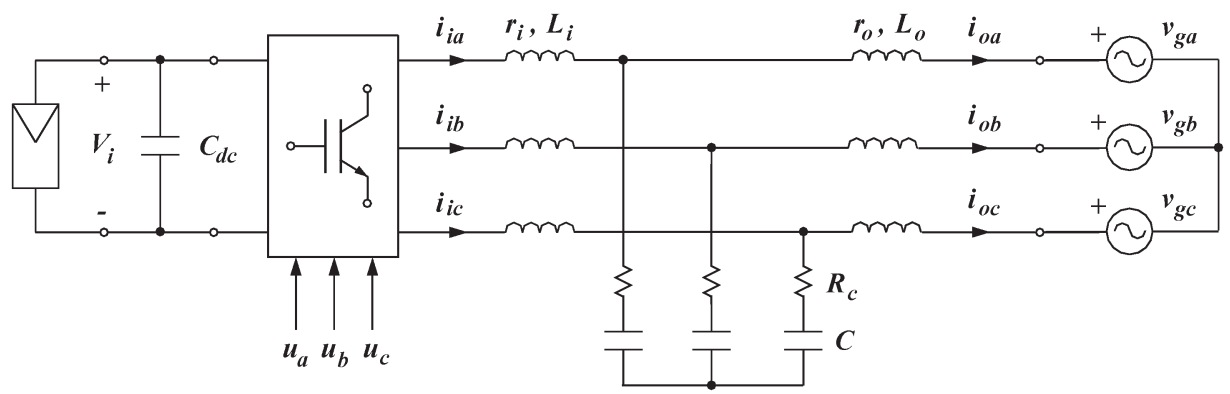

Fig. 1. Diagram of the three-phase PV inverter.

[35] and [36]. The novel control configuration is also different to the standard resonant control [24]. As confirmed hereinafter, the proposed control improves the current harmonic distortion even in the case that the current references exhibit distorted waveforms. Thus, the main contribution of this work is the novel resonant current control intended for three-phase applications which features high harmonic rejection capability and low computational load as compared with the standard resonant current control.

This paper is organized as follows. Section II models the three-phase PV inverter. Section III analyzes the standard resonant control and reveals its limitations. Section IV presents the proposed control and discusses its main features. Section V reports on selected experimental results from a three-phase PV inverter prototype. This practical work verifies the expected features of the proposed control. Section VI is the conclusion.

\section{Three-Phase DG PV InVERTER}

Fig. 1 shows the diagram of the three-phase PV inverter. It includes a PV array, a dc-link capacitor, and a three-phase voltage-source inverter. The switches of the inverter are governed by the discrete variables $u$, which can take the value -1 or 1 . The inverter employs an $L C L$ filter to reduce the highfrequency switching harmonics [23]. Small resistive parasitic elements are considered in this filter. Also, a damping resistor is intentionally introduced in series with the capacitors in order to attenuate the $L C L$ peak magnitude at the resonance frequency. Normally, the losses in this resistor are negligible [1]. The utility grid is modeled as three ac voltage sources.

\section{A. Open-Loop Model of the Three-Phase PV Inverter}

The starting point for the analysis of the resonant current control is an averaged model of the three-phase PV inverter [23], [38]. A circuit representation of this averaged model in the stationary reference frame is shown in Fig. 2. The inputs of the model are the dc-link voltage $V_{i}$, the grid voltage $v_{g}$, and the control inputs $d$, which can take continuous values inside the range

$$
\begin{aligned}
& -1 \leq d_{\alpha} \leq 1 \\
& -1 \leq d_{\beta} \leq 1 .
\end{aligned}
$$

The outputs of the model are the inverter current $i_{i}$ and the grid current $i_{o}$.

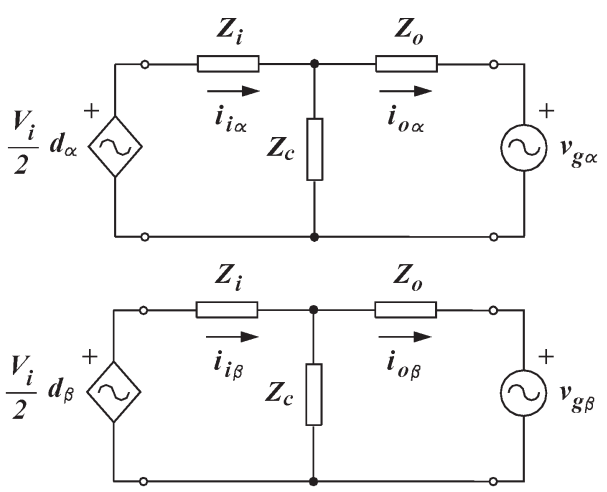

Fig. 2. Averaged circuit model of the three-phase PV inverter, where $Z_{i}(s)=$ $L_{i} s+r_{i}, Z_{o}(s)=L_{o} s+r_{o}, Z_{c}(s)=1 /(C s)+R_{c}$, and $s$ is the Laplace operator.
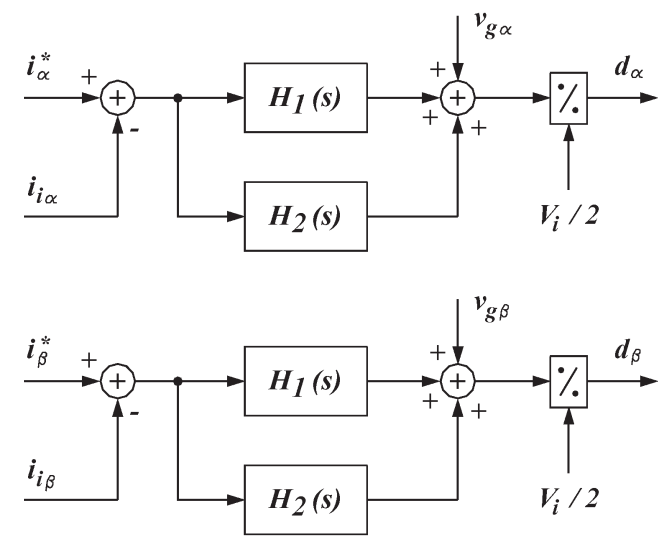

Fig. 3. Standard resonant current control in the stationary reference frame.

\section{B. Resonant Current Control}

Fig. 3 shows the standard configuration of the resonant current control [24]. The error between the inverter current and the reference signal is processed by two compensators connected in parallel: the PRES compensator $H_{1}(s)$ and the RESH compensator $\mathrm{H}_{2}(s)$. The inverter current is normally employed in the control instead of the grid current. This fact reduces the number of the required current sensors and increases the system robustness [1]. The grid voltage and the dc-link voltage are used as feedforward signals in order to improve the dynamics of the system. The system capability to reject external disturbances is 
also enhanced with these feedforward signals [38]. From Fig. 3, the control inputs can be written as

$$
\begin{aligned}
& d_{\alpha}=\frac{2}{V_{i}}\left[v_{g \alpha}+\left(H_{1}(s)+H_{2}(s)\right)\left(i_{\alpha}^{*}-i_{i \alpha}\right)\right] H_{d}(s) \\
& d_{\beta}=\frac{2}{V_{i}}\left[v_{g \beta}+\left(H_{1}(s)+H_{2}(s)\right)\left(i_{\beta}^{*}-i_{i \beta}\right)\right] H_{d}(s) .
\end{aligned}
$$

$H_{d}(s)$, not shown in Fig. 3, is the transfer function that models the control processing time delay $T_{d}[1]$

$$
H_{d}(s)=e^{-T_{d} s} .
$$

\section{Closed-Loop Model of the Three-Phase PV Inverter}

The analysis of the system can be carried out by means of a closed-loop dynamic model. This model is derived by placing (3) and (4) into the open-loop model shown in Fig. 2, resulting in

$$
\begin{aligned}
& i_{o \alpha}(s)=G_{r}(s) i_{\alpha}^{*}(s)+G_{g}(s) v_{g \alpha}(s) \\
& i_{o \beta}(s)=G_{r}(s) i_{\beta}^{*}(s)+G_{g}(s) v_{g \beta}(s)
\end{aligned}
$$

where the reference-signal-to-grid-current transfer function and the grid-voltage-to-grid-current transfer function can be expressed, respectively, as

$$
\begin{aligned}
G_{r}(s) & =\frac{Z_{c}(s) G_{i}(s)\left(H_{1}(s)+H_{2}(s)\right) H_{d}(s)}{1+T(s)} \\
G_{g}(s) & =-\frac{G_{i}(s)\left(Z_{i}(s)+\left(H_{1}(s)+H_{2}(s)\right) H_{d}(s)\right)}{1+T(s)} .
\end{aligned}
$$

Moreover, the loop gain $T(s)$ and the transfer function $G_{i}(s)$ can be written as

$$
\begin{aligned}
T(s)= & \left(Z_{c}(s)+Z_{o}(s)\right) G_{i}(s) \\
& \times\left(H_{1}(s)+H_{2}(s)\right) H_{d}(s) \\
G_{i}(s)= & \frac{1}{Z_{i}(s)\left(Z_{c}(s)+Z_{o}(s)\right)+Z_{c}(s) Z_{o}(s)} .
\end{aligned}
$$

It is worth mentioning that the closed-loop dynamics of the grid current does not rely on the dc-link voltage; see (6) and (7). Essentially, this fact can be attributed to the feedforward action introduced in (3) and (4) by the dc-link voltage signal. Note that a feedforward signal of the grid voltage is also included in the control inputs (3) and (4). However, in that case, the closed-loop dynamics of the grid current is directly affected by the grid voltage disturbances through the transfer function $G_{g}(s)$. As discussed hereinafter, this transfer function presents significant magnitude attenuation in the frequency range of interest. Therefore, the direct influence of the grid voltage disturbances on the grid current is nearly negligible.

\section{ANALYSis AND Limitations OF THE STANDARD RESONANT CURRENT CONTROL}

The standard resonant current control employs two resonant compensators connected in parallel, as shown in Fig. 3 [23],
TABLE I

PARAMETERS OF THE THREE-PHASE DG PV System

\begin{tabular}{lll}
\hline \hline Symbol & \multicolumn{1}{c}{ Quantity } & \multicolumn{1}{c}{ Nominal value } \\
\hline$P_{m}$ & maximum output power & $3.2 \mathrm{~kW}$ \\
$f_{s}$ & switching frequency & $10 \mathrm{kHz}$ \\
$V_{i, o c}$ & open-circuit PV array output voltage & $750 \mathrm{~V}$ \\
$I_{i, s c}$ & short-circuit PV array output current & $5.4 \mathrm{~A}$ \\
$V_{i, m p}$ & maximum-power PV output voltage & $650 \mathrm{~V}$ \\
$I_{i, m p}$ & maximum-power PV output current & $4.9 \mathrm{~A}$ \\
$L_{i}$ & inverter side inductances & $6.9 \mathrm{mH}$ \\
$r_{i}$ & inverter side parasitic resistances & $0.27 \Omega$ \\
$C$ & filter capacitors & $680 \mathrm{nF}$ \\
$R_{c}$ & filter damping resistances & $6.8 \Omega$ \\
$L_{O}$ & grid side inductances & $2.1 \mathrm{mH}$ \\
$r_{O}$ & grid side parasitic resistances & $0.14 \Omega$ \\
$V_{g}$ & grid voltage (rms, phase to neutral) & $200 \mathrm{~V}$ \\
$f_{o}$ & grid frequency & $50 \mathrm{~Hz}$ \\
$k_{p}$ & proportional gain & $60 \Omega$ \\
$k_{i 1}$ & fundamental integral gain & $300 \Omega \mathrm{s}^{2}$ \\
$k_{i n}$ & n-harmonic integral gain & $300 \Omega \mathrm{s}^{2}$ \\
$\xi_{1}$ & fundamental damping factor & 0.01 \\
$\xi_{n}$ & n-harmonic damping factor & 0.01 \\
$n$ & selected harmonics to be attenuated & $5,7,11,13$ \\
$T_{d}$ & control processing delay time & $100 \mu \mathrm{s}$ \\
\hline \hline & & \\
\hline
\end{tabular}

[24]. The PRES compensator ensures the correct tracking of the fundamental component of the current reference signal. The RESH compensator attenuates the selected grid current harmonics. Both compensators can be written as follows [15], [22], [35]:

$$
\begin{aligned}
& H_{1}(s)=k_{p}+\frac{k_{i 1} 2 \xi_{1} \omega_{o} s}{s^{2}+2 \xi_{1} \omega_{o} s+\omega_{o}^{2}} \\
& H_{2}(s)=\sum_{n} \frac{k_{i n} 2 \xi_{n}\left(n \omega_{o}\right) s}{s^{2}+2 \xi_{n}\left(n \omega_{o}\right) s+\left(n \omega_{o}\right)^{2}} .
\end{aligned}
$$

Table I defines the parameters of these compensators and lists the values used in this work. Also, the values of the three-phase system are given in Table I. The power circuit components have been chosen following the design guidelines reported in [23]. Fig. 4 shows the Bode magnitude diagram of the resonant compensators.

The features of the standard resonant current control emerge from the analysis of the transfer functions (8)-(10). The Bode diagrams of these functions are shown in Fig. 5. Note that the system is stable with a phase margin of $38.4^{\circ}$ at the crossover frequency of $1.1 \mathrm{kHz}$; see Fig. 5(a). Moreover, the gridvoltage-to-grid-current transfer function $G_{g}(s)$ has significant magnitude attenuation in the frequency range of interest (i.e., $G_{g}(s) \rightarrow 0$ in this frequency range); see Fig. 5(b). Thus, from (6), it is easy to observe that the grid voltage disturbances do not directly affect the grid current dynamics. Additionally, the reference-signal-to-grid-current transfer function $G_{r}(s)$ has a 


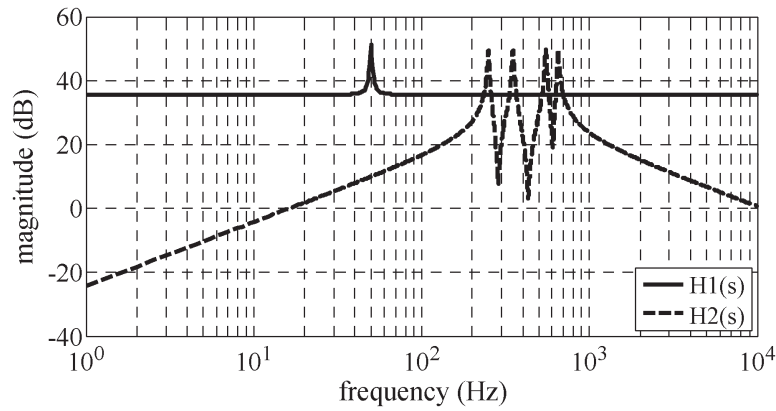

Fig. 4. Bode magnitude diagram of the PRES and RESH compensators employed in the standard resonant current control.

flat 0-dB magnitude within the system bandwidth; see Fig. 5(c). This ensures that the grid current tracks accurately the reference signal, even in the undesired situation in which this signal has significant harmonics. Consequently, from (6), the harmonic distortion present in the reference signal will be transferred to the grid current. The reference signal harmonic distortion may be caused by grid disturbances such as voltage harmonics or imbalances. This is, in fact, an indirect mechanism to increase the output current harmonic distortion through grid voltage disturbances when using the standard resonant current control.

\section{Proposed Resonant Current Control}

The main objective of the proposed control is to achieve low harmonic distortion in the grid current even during grid abnormal conditions. This feature should be accomplished without increasing the control computational load.

\section{A. Control Configuration}

Fig. 6 shows the diagram of the proposed control scheme. Note that the configuration is very similar to the standard control shown in Fig. 3. Both the grid voltage and the dclink voltage are included as feedforward signals. The proposed control also has two resonant compensators, but in that case, the input of the compensator located on the bottom is the inverter current instead of the error between this current and the reference signal. This is one of the differences between the standard and the proposed control schemes. The second one is the configuration of the resonant compensators. The control objectives are reached if the resonant compensators are chosen as follows:

$$
\begin{aligned}
& H_{3}(s)=\frac{k_{i 1} 2 \xi_{1} \omega_{o} s}{s^{2}+2 \xi_{1} \omega_{o} s+\omega_{o}^{2}} \\
& H_{4}(s)=k_{p}+\sum_{n} \frac{k_{i n} 2 \xi_{n}\left(n \omega_{o}\right) s}{s^{2}+2 \xi_{n}\left(n \omega_{o}\right) s+\left(n \omega_{o}\right)^{2}} .
\end{aligned}
$$

Note that the first compensator includes only the fundamental resonant term and the second compensator compresses both the proportional and the harmonic resonant terms. It is worth mentioning that

$$
H_{1}(s)+H_{2}(s)=H_{3}(s)+H_{4}(s)
$$

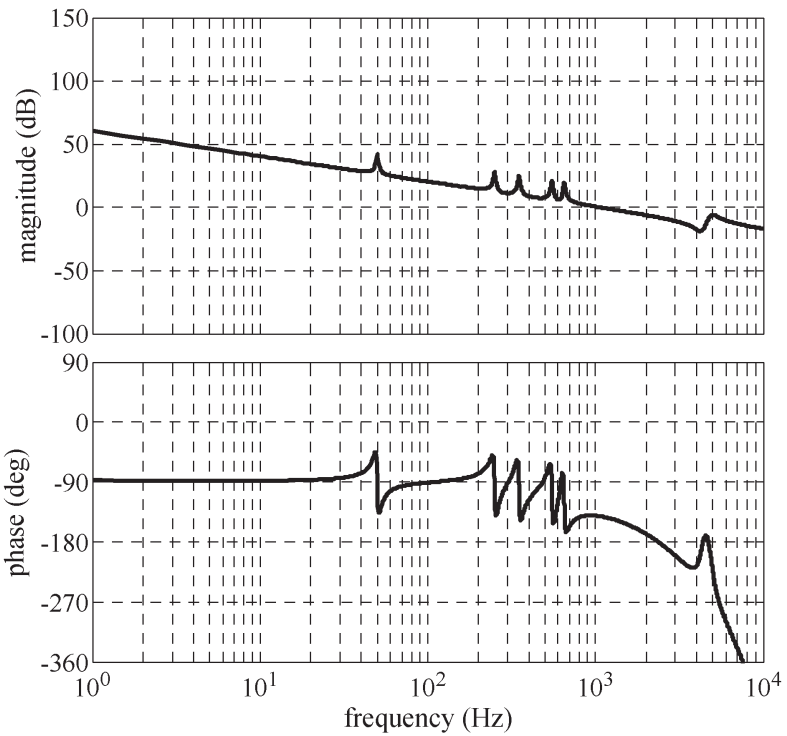

(a)

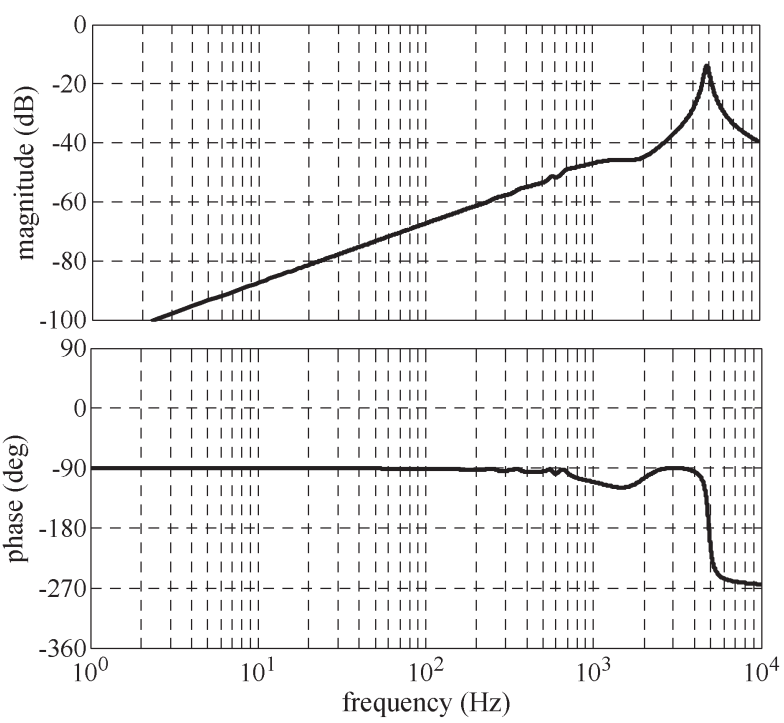

(b)

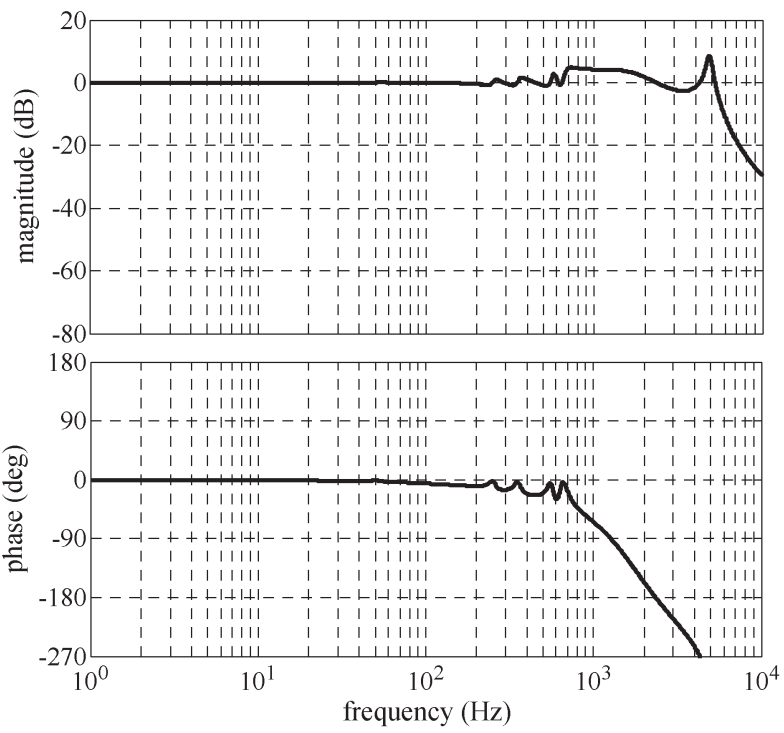

(c)

Fig. 5. Bode diagrams of the standard resonant current control. (a) Loop gain transfer function $T(s)$, (b) grid-voltage-to-grid-current transfer function $G_{g}(s)$, and (c) reference-signal-to-grid-current transfer function $G_{r}(s)$. 

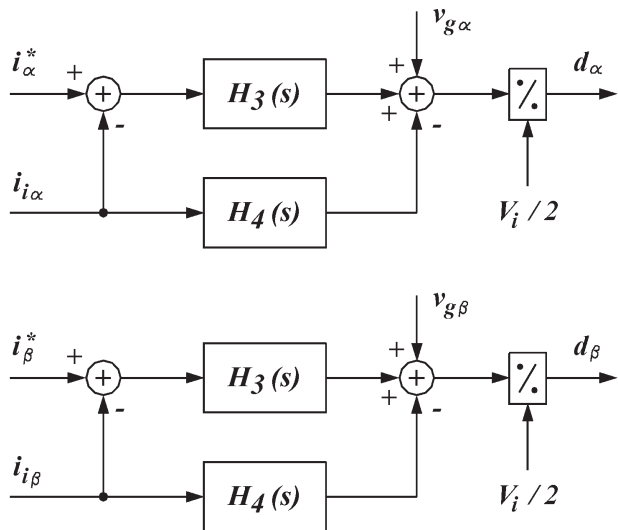

Fig. 6. Proposed resonant current control.

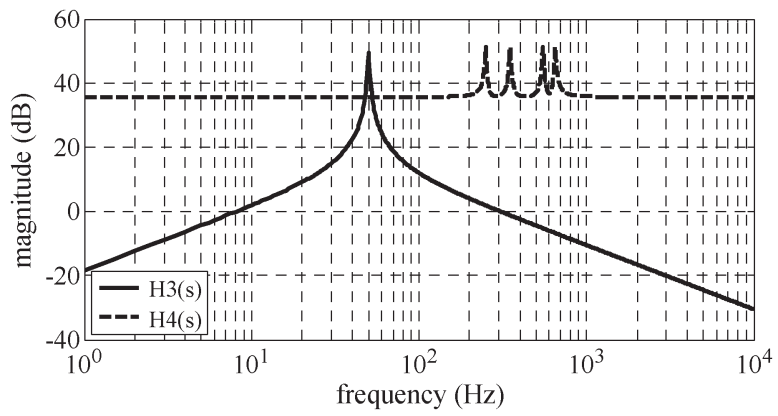

Fig. 7. Bode magnitude diagram of the compensators employed in the proposed resonant current control.

so that it is expected to achieve the same computational load with both control schemes. Fig. 7 shows the Bode diagram of the proposed compensators.

\section{B. Closed-Loop Transfer Functions}

From Fig. 6, the control inputs of the proposed scheme can be written as

$$
\begin{aligned}
d_{\alpha} & =\frac{2}{V_{i}}\left[v_{g \alpha}+H_{3}(s)\left(i_{\alpha}^{*}-i_{i \alpha}\right)-H_{4}(s) i_{i \alpha}\right] H_{d}(s) \\
d_{\beta} & =\frac{2}{V_{i}}\left[v_{g \beta}+H_{3}(s)\left(i_{\beta}^{*}-i_{i \beta}\right)-H_{4}(s) i_{i \beta}\right] H_{d}(s) .
\end{aligned}
$$

The closed-loop transfer functions of the proposed control are derived by inserting (17) and (18) in the open-loop model shown in Fig. 2, resulting in

$$
\begin{aligned}
T(s)= & \left(Z_{c}(s)+Z_{o}(s)\right) G_{i}(s)\left(H_{3}(s)+H_{4}(s)\right) \\
& \times H_{d}(s) \\
G_{r}(s)= & \frac{Z_{c}(s) G_{i}(s) H_{3}(s) H_{d}(s)}{1+T(s)} \\
G_{g}(s)= & -\frac{G_{i}(s)\left(Z_{i}(s)+\left(H_{3}(s)+H_{4}(s)\right) H_{d}(s)\right)}{1+T(s)} .
\end{aligned}
$$

It is worth mentioning that the aforementioned transfer functions do not rely on the steady-state values of $d$ and $V_{i}$, as usual [22], [35]. This fact can be attributed to the use of the

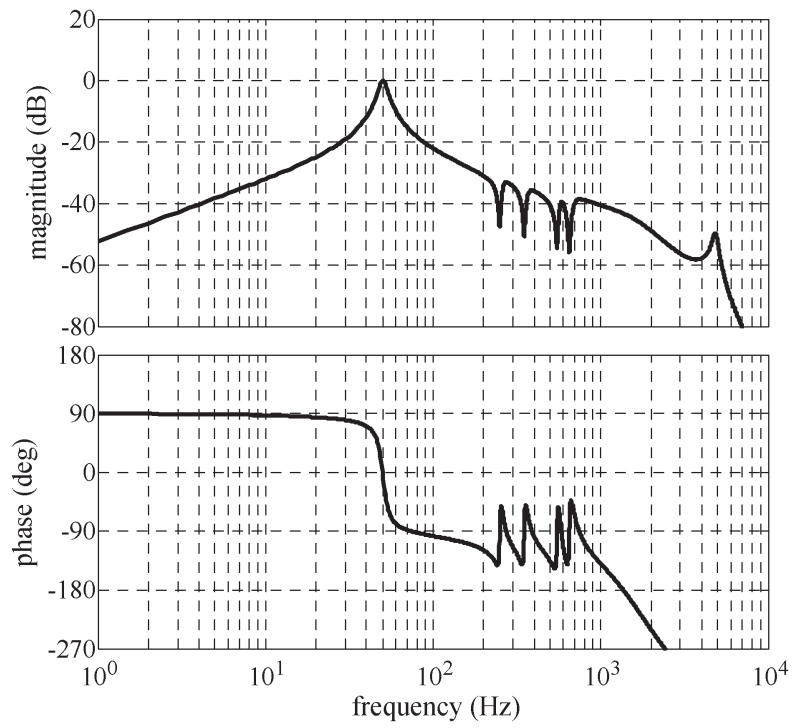

Fig. 8. Bode diagram of the reference-signal-to-grid-current transfer function for the proposed resonant current control.

feedforward signal $V_{i}$ in the control input generation; see (3) and (4).

Taking into account (16), it is easy to prove that the loop gain and the grid-voltage-to-grid-current transfer functions coincide with (9) and (10). As a consequence, the measures obtained from Fig. 5(a) and (b), including the relative stability, crossover frequency, and direct rejection capability of grid voltage disturbances, are also valid for the proposed control scheme. The reference-signal-to-grid-current transfer function is, however, quite different from that shown in Fig. 5(c). Instead of a flat shape, Fig. 8 shows that this transfer function has a bandpass filter behavior. Note that 0 -dB gain is only achieved at the grid frequency. In addition, high dips in the magnitude diagram are noticed at the selected harmonic frequencies $(250,350,550$, and $650 \mathrm{~Hz}$ ). It is interesting to note that interharmonics with frequencies not located in the vicinity of integer harmonics will experience a high attenuation. This is a promising feature of the proposed control scheme which is not shared by the standard control scheme; see Fig. 5(c). As a consequence, an accurate tracking of the fundamental component of the current reference signal is expected in the proposed control scheme. Also, the reference signal integer harmonics and interharmonics are strongly attenuated, and therefore, a low harmonic distortion of the grid current is also expected in the proposed control scheme.

\section{EXPERIMENTAL RESUlTS}

This section verifies experimentally the proposed control. A performance comparison with the standard and some selected advanced controls is also reported.

\section{A. Experimental Setup}

Fig. 9 shows the experimental setup of the three-phase grid-connected PV inverter system. It consists of a dc source configured to emulate the PV array (Amrel SPS-800-12D013), a 4.5-kVA Semikron three-phase inverter, and an ac 


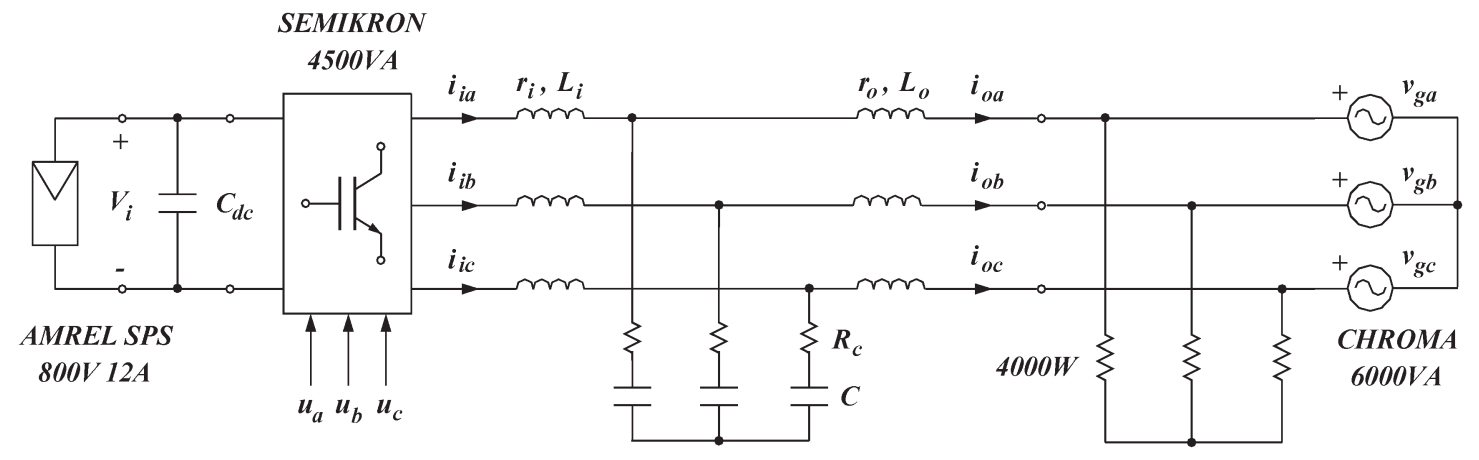

Fig. 9. Experimental setup of the three-phase grid-connected PV inverter system.

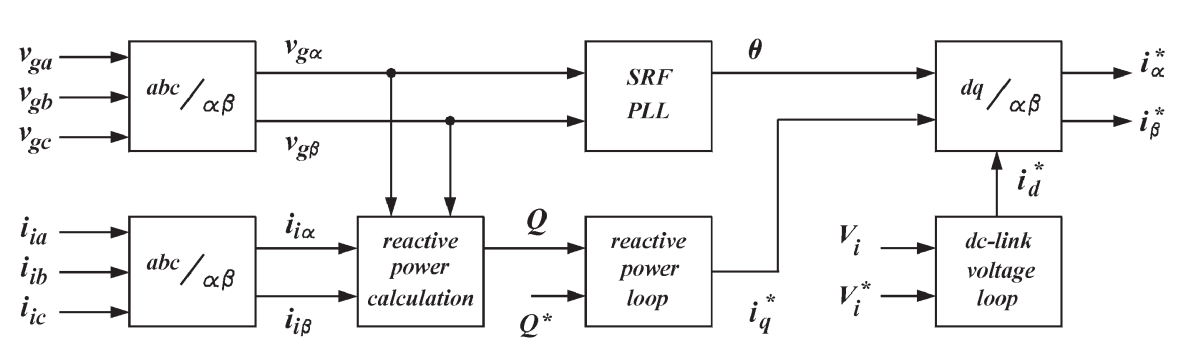

(a)

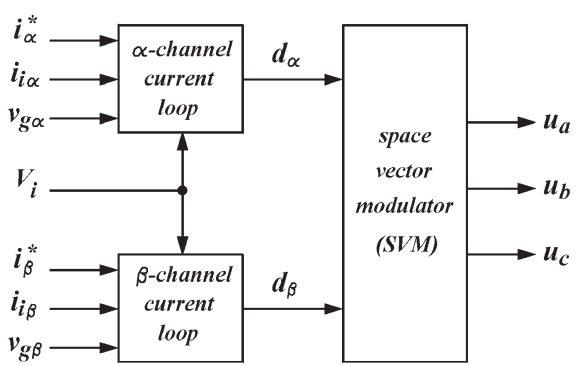

(b)

Fig. 10. Diagram of the complete control system. (a) External control loops. (b) Internal control loops and modulator. The standard configuration of these internal loops is shown in Fig. 3. The configuration proposed in this paper is shown in Fig. 6.

programmable source (Chroma 61704). The experimental setup is completed with a $4-\mathrm{kW}$ resistive load connected in parallel with the ac source. This local load is necessary in the setup since the ac source cannot absorb the active power injected by the inverter.

The digital control platform employed in the setup is based on a floating-point TMS320F28335 DSP. Fig. 10 shows a diagram of the complete control system. It includes the conventional external control loops, i.e., the dc-link voltage regulation loop, the reactive power regulation loop, and the PLL [24]. The diagram of the internal control loops and the space vector modulator is shown in Fig. 10(b). Details on the discrete implementation of the resonant compensators can be found in [37]. The values of the control loop parameters are listed in Tables I and II.

\section{B. Current THD Measures}

An extensive set of measures has been carried out in order to compare the current harmonic distortion provided by the standard and the proposed control schemes. The first set of experiments considers an ideal grid situation, i.e., the voltage supplied by the ac source has both negligible harmonics and no appreciable imbalance. In that situation, the standard and the proposed schemes provide very similar results (not shown here).

The second set of experiments considers a grid with high voltage distortion. The experimental waveforms for this case are shown in Fig. 11, and the THD measures are listed in Table III. Different voltage harmonic contents were programmed in the ac source for each grid phase to reproduce a challenging practical situation. Note that the performance of the
TABLE II

PARAMETERS OF THE EXTERNAL CONTROL LOOPS

\begin{tabular}{lll}
\hline \hline Symbol & \multicolumn{1}{c}{ Quantity } & \multicolumn{1}{c}{ Nominal value } \\
\hline$f_{m}$ & sampling frequency & $10 \mathrm{kHz}$ \\
$k_{p, p}$ & proportional gain of SRF PLL & $1.77 \mathrm{rad} /(\mathrm{Vs})$ \\
$k_{i, p}$ & integral gain of SRF PLL & $157.91 \mathrm{rad} /\left(\mathrm{Vs}^{2}\right)$ \\
$Q^{*}$ & $\begin{array}{l}\text { reference signal of the reactive power } \\
\text { control loop (Q loop) }\end{array}$ & $0 \mathrm{VAr}$ \\
$k_{p, q}$ & proportional gain of the Q loop & $0.0001(\mathrm{~V})^{-1}$ \\
$k_{i, q}$ & integral gain of the Q loop & $0.001(\mathrm{Vs})^{-1}$ \\
$V_{i}^{*}$ & $\begin{array}{l}\text { reference signal of the dc-link voltage } \\
\text { control loop (DC-link loop) }\end{array}$ & $650 \mathrm{~V}$ \\
$k_{p, v}$ & proportional gain of the DC-link loop & $0.005 \mathrm{~A} / \mathrm{V}$ \\
$k_{i, v}$ & integral gain of the DC-link loop & $0.01 \mathrm{~A} /(\mathrm{Vs})$ \\
\hline \hline
\end{tabular}

standard current control is poor when the RESH compensator is not employed. In particular, phase $c$ current has a harmonic distortion that exceeds the THD limits [12]. The activation of the RESH compensator improves the performance of the standard current control. In fact, the current THD is drastically reduced in this case, and all measures are well below the 5\% limit. The proposed control further reduces the harmonic distortion and leads the current THD to almost negligible levels.

The last set of experiments considers a grid with voltage harmonics and imbalances. The grid voltage is characterized as $1 \angle 0^{\circ}, 0.76 \angle 131^{\circ}$, and $0.76 \angle 229^{\circ}$, where magnitudes are expressed in per unit and phases are expressed in degrees. Fig. 12 and Table IV show the experimental measures. Note that the current has experienced an increase due to the reduction 


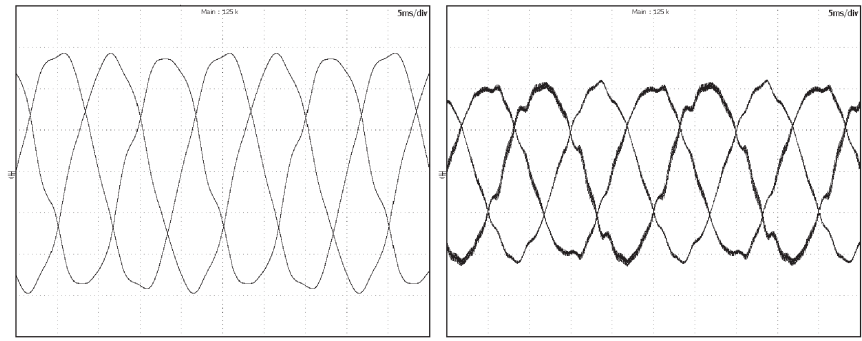

(a)

(b)

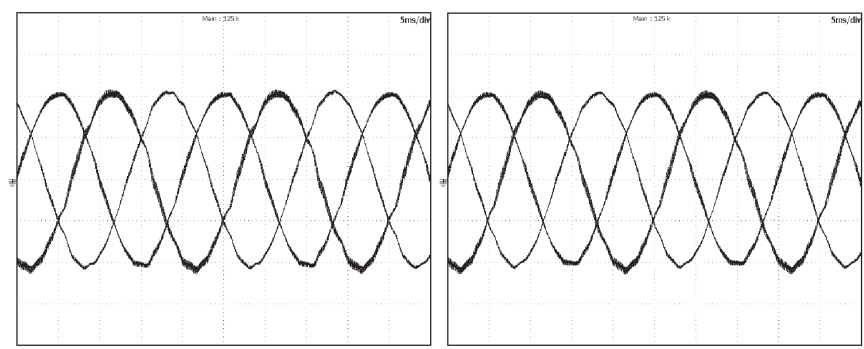

(c)

(d)

Fig. 11. Experimental results for a grid condition with high voltage THD. (a) Grid voltage (100 V/div). Inverter current (3.2 A/div) using (b) the standard control without RESH compensator, (c) the standard control with RESH compensator, and (d) the proposed control.

TABLE III

Grid CuRRent THD (IN PERCENT) FOR A GRID CONDITION With High Voltage THD (IN PeRcent)

\begin{tabular}{ccccccc}
\hline \hline Control scheme & $v_{g a}$ & $v_{g b}$ & $v_{g c}$ & $i_{o a}$ & $i_{o b}$ & $i_{o c}$ \\
\hline Standard w/o RESH & 4.0 & 4.5 & 7.5 & 3.6 & 3.4 & 5.7 \\
Standard with RESH & 3.7 & 4.7 & 7.8 & 1.8 & 1.8 & 2.3 \\
Proposed control & 3.8 & 4.8 & 7.8 & 1.0 & 1.2 & 1.5 \\
\hline \hline
\end{tabular}

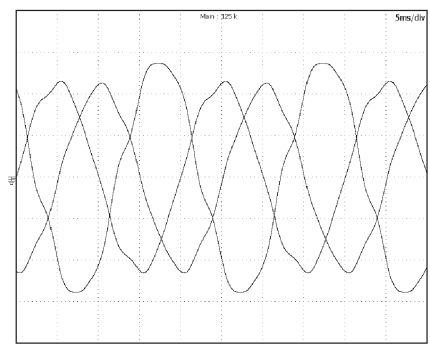

(a)

(c)

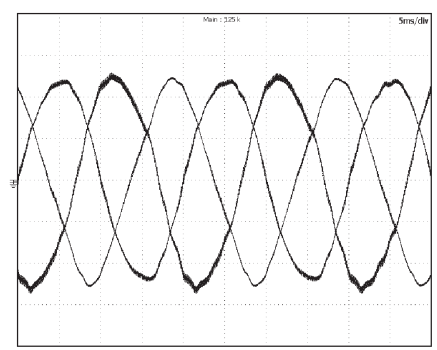

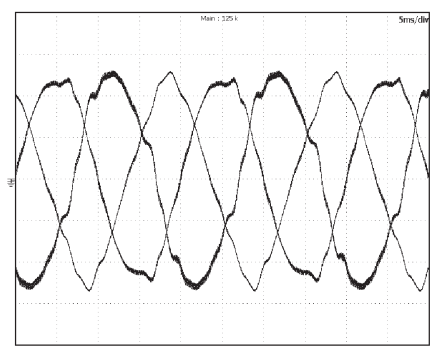

(b)

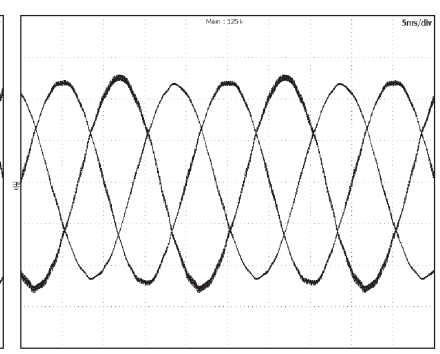

(d)
Fig. 12. Experimental results for a grid condition with high voltage THD and voltage imbalance. (a) Grid voltage (100 V/div). Inverter current (3.2 A/div) using (b) the standard control without RESH compensator, (c) the standard control with RESH compensator, and (d) the proposed control.
TABLE IV

GRID CURRENT THD (IN PERCENT) FOR A GRID CONDITION With High Voltage THD (In Percent) And Voltage Imbalance

\begin{tabular}{ccccccc}
\hline \hline Control scheme & $v_{g a}$ & $v_{g b}$ & $v_{g c}$ & $i_{o a}$ & $i_{o b}$ & $i_{o c}$ \\
\hline Standard w/o RESH & 5.3 & 5.5 & 7.2 & 6.9 & 6.0 & 6.6 \\
Standard with RESH & 5.2 & 5.5 & 7.4 & 6.2 & 5.3 & 5.1 \\
Proposed control & 5.3 & 5.6 & 7.4 & 1.0 & 1.0 & 1.3 \\
\hline \hline
\end{tabular}

TABLE V

COMPARISON OF RESONANT CURRENT CONTROL SCHEMES

\begin{tabular}{cccc}
\hline \hline $\begin{array}{c}\text { Resonant current } \\
\text { control scheme }\end{array}$ & \multicolumn{2}{c}{ Total execution time } \\
$\mu \mathrm{S}$ & $\%$ & $\begin{array}{c}\text { Abnormal grid } \\
\text { performance }\end{array}$ \\
\hline Standard w/o RESH & 13.6 & 42.1 & poor \\
Standard with RESH & 17.5 & 54.2 & medium \\
Proposed control & 17.5 & 54.2 & good \\
Advanced control 1 & 32.3 & 100 & excellent \\
Advanced control 2 & 24.2 & 74.9 & good \\
Advanced control 3 & 26.7 & 82.7 & excellent \\
\hline \hline
\end{tabular}

of the grid voltage. Basically, the dc-link voltage control loop has enlarged the amplitude of the current reference signals in order to maintain constant the injection of the active power. What is more important is that the standard control produces unsatisfactory results. The current THD of the three phases exceeds the limit even when the RESH compensator is used. On the contrary, the proposed control provides good results. The current THD is low and similar to the value measured when the grid has no voltage imbalance. This feature should be attributed to the ability of the proposed control to eliminate the harmonics present in the current reference signals. It is worth mentioning that the injected currents exhibit a small amplitude mismatch produced by the voltage imbalance. It is expected that this small mismatch has insignificant adverse effects on the power system.

\section{Computational Load Measures}

The execution time of the previously described resonant current control schemes has been measured. Table V lists the total computing time of the complete control systems, including external control loops, internal control loops, and modulator. Note that the proposed control has the same computational load as the standard control with RESH compensators but with a higher current harmonic rejection capability (as verified in the previous section).

A performance comparison with several advanced control schemes is also reported. Advanced control 1 is a current control formulated in the synchronous reference frame [29]. It uses positive and negative sequence components to generate the current references. Also presented in [29], advanced control 2 is a current control formulated in the natural $a b c$ frame. It exhibits a reduced execution time in comparison with advanced control 1 because multiple reference frames and symmetrical sequence components are not required. However, 
a PLL algorithm capable of measuring positive and negative instantaneous phases is required in both advanced controls, which increase the complexity of these control systems. In this study, the PLL algorithm presented in [30] is employed to measure the execution time of these control schemes. Advanced control 3 is a current control formulated in the stationary reference frame [31]. Based on the ideas introduced in [32] and [33], this control also uses symmetrical sequence components for the current reference generation. For practical application, this control scheme requires a sophisticated frequency-locked loop (FLL) for grid synchronization. The FLL presented in [34] is used in this work to measure the execution time of this control approach. As a final remark, from Table V, it can be concluded that the proposed control is an intermediate solution with good enough performance and low computational load.

\section{CONCLUSION}

A resonant current control intended for three-phase PV inverters connected to the utility grid has been presented in this paper. The limitations of previous control schemes that employ resonant compensators both to accurately track the fundamental component of the current reference signals and to attenuate the most important current harmonics have been highlighted. An indirect mechanism that produces current harmonics from abnormal grid situations (such as voltage harmonics and imbalances) through the inadequate operation of the external control loops has been identified. The proposed resonant control breaks the disturbance injection mechanism by employing the same compensators that the standard current control uses but interconnected in a different configuration. As a result, the main contribution of this paper is to introduce a resonant current control scheme which features low current harmonic distortion and low computational load. In fact, the computational load is exactly the same as that of the standard resonant current control while the current harmonic distortion is significantly reduced, particularly during grid abnormal conditions. Selected experimental results from a three-phase grid-connected PV inverter have been reported confirming the expected features of the proposed control scheme.

\section{REFERENCES}

[1] E. Figueres, G. Garcerá, J. Sandia, F. González-Espin, and J. C. Rubio, "Sensitivity study of the dynamics of three-phase photovoltaic inverters with an LCL grid filter," IEEE Trans. Ind. Electron., vol. 56, no. 3, pp. 706-717, Mar. 2009.

[2] M. C. Cavalcanti, K. C. de Oliveira, A. M. de Farias, F. A. Neves, G. M. Azevedo, and F. C. Camboim, "Modulation techniques to eliminate leakage currents in transformerless three-phase photovoltaic systems," IEEE Trans. Ind. Electron., vol. 57, no. 4, pp. 1360-1368, Apr. 2010.

[3] M. Cacciato, A. Consoli, R. Attanasio, and F. Gennaro, "Soft-switching converter with HF transformer for grid-connected photovoltaic systems," IEEE Trans. Ind. Electron., vol. 57, no. 5, pp. 1678-1686, May 2010.

[4] S. V. Araujo, P. Zacharias, and R. Mallwitz, "Highly efficient single-phase transformerless inverters for grid-connected photovoltaic systems," IEEE Trans. Ind. Electron., vol. 57, no. 9, pp. 3118-3128, Sep. 2010.

[5] R. Kadri, J. P. Gaubert, and G. Champenois, "An improved maximum power point tracking for photovoltaic grid-connected inverter based-on voltage oriented control," IEEE Trans. Ind. Electron., vol. 58, no. 1, pp. 66-75, Jan. 2011.

[6] A. I. Bratcu, I. Munteanu, S. Bacha, D. Picault, and B. Raison, "Cascaded dc-dc converter photovoltaic systems: Power optimization issues," IEEE Trans. Ind. Electron., vol. 58, no. 2, pp. 403-411, Feb. 2011.
[7] Q. Mai, M. Shan, L. Liu, and J. M. Guerrero, "A novel improved variable step-size incremental-resistance MPPT method for PV systems," IEEE Trans. Ind. Electron., vol. 58, no. 6, pp. 2427-2434, Jun. 2011.

[8] N. A. Rahim, K. Chaniago, and J. Selvaraj, "Single-phase sevenlevel grid-connected inverter for photovoltaic system," IEEE Trans. Ind. Electron., vol. 58, no. 6, pp. 2435-2443, Jun. 2011.

[9] I. J. Balaguer, Q. Lei, S. Yang, U. Supatti, and F. Z. Peng, "Control for grid-connected and intentional islanding operations of distributed power generation," IEEE Trans. Ind. Electron., vol. 58, no. 1, pp. 147-157, Jan. 2011.

[10] J. M. Guerrero, J. C. Vasquez, J. Matas, L. Garcia de Vicuna, and M. Castilla, "Hierarchical control of droop-controlled ac and dc microgrids-A general approach toward standardization," IEEE Trans. Ind. Electron., vol. 58, no. 1, pp. 158-172, Jan. 2011.

[11] C. Yuen, A. Oudalov, and A. Timbus, "The provision of frequency control reserves from multiple microgrids," IEEE Trans. Ind. Electron., vol. 58, no. 1, pp. 173-183, Jan. 2011.

[12] Characteristics of the Utility Interface for Photovoltaic (PV) Systems, IEC61727, Dec. 2004.

[13] IEEE Standard for Interconnecting Distributed Resources With Electric Power Systems, IEEE15471, 2008.

[14] 2002 National Electrical Code, Nat. Fire Protection Assoc., Inc., Quincy, MA, 2002.

[15] D. N. Zmood, D. G. Holmes, and G. H. Bode, "Frequency-domain analysis of three-phase linear current regulators," IEEE Trans. Ind. Appl., vol. 37, no. 2, pp. 601-610, Mar./Apr. 2001.

[16] X. Yuan, W. Merk, H. Stemmler, and J. Allmeling, "Stationary-frame generalized integrators for current control of active power filters with zero steady-state error for current harmonics of concern under unbalanced and distorted operating conditions," IEEE Trans. Ind. Appl., vol. 38, no. 2, pp. 523-532, Mar./Apr. 2002.

[17] D. N. Zmood and D. G. Holmes, "Stationary frame current regulation of PWM inverters with zero steady-state error," IEEE Trans. Power Electron., vol. 18, no. 3, pp. 814-822, May 2003.

[18] M. Liserre, R. Teodorescu, and F. Blaabjerg, "Multiple harmonics control for three-phase grid converter systems with the use of PI-RES current controller in a rotating frame," IEEE Trans. Power Electron., vol. 21, no. 3, pp. 836-841, May 2006.

[19] G. Shen, X. Zhu, J. Zhang, and D. Xu, "A new feedback method for PR current control of LCL-filter-based grid-connected inverter," IEEE Trans. Ind. Electron., vol. 57, no. 6, pp. 2033-2041, Jun. 2010.

[20] K. Lee, T. M. Jahns, T. A. Lipo, and V. Blasko, "New control method including state observer of voltage unbalance for grid voltage-source converters," IEEE Trans. Ind. Electron., vol. 57, no. 6, pp. 2054-2065, Jun. 2010.

[21] T. L. Lee and S. H. Hu, "Resonant current compensator with enhancement of harmonic impedance for LCL-filter based active rectifiers," in Proc. IEEE APEC, 2011, pp. 1538-1543.

[22] M. Castilla, J. Miret, J. Matas, L. Garcia de Vicuna, and J. M. Guerrero, "Control design guidelines for single-phase grid-connected photovoltaic inverters with damped resonant harmonics compensators," IEEE Trans. Ind. Electron., vol. 56, no. 11, pp. 4492-4501, Nov. 2009.

[23] M. Liserre, R. Teodorescu, and F. Blaabjerg, "Stability of photovoltaic and wind turbine grid-connected inverters for a large set of grid impedance values," IEEE Trans. Power Electron., vol. 21, no. 1, pp. 263-272, Jan. 2006.

[24] F. Blaabjerg, R. Teodorescu, M. Liserre, and A. V. Timbus, "Overview of control and grid synchronization for distributed power generation systems," IEEE Trans. Ind. Electron., vol. 53, no. 5, pp. 1398-1409, Oct. 2006.

[25] J. Hu, Y. He, L. Xu, and B. Williams, "Improved control of DFIG systems during network unbalance using PI-R current regulators," IEEE Trans. Ind. Electron., vol. 56, no. 2, pp. 439-451, Feb. 2009.

[26] M. Andreica Vallet, S. Bacha, I. Munteanu, I. Bratcu, and D. Roye, "Management and control of operating regimes of cross-flow water turbines," IEEE Trans. Ind. Electron., vol. 58, no. 5, pp. 1866-1876, May 2011.

[27] S. Y. Park, C. L. Chen, J. S. Lai, and S. R. Moon, "Admittance compensation in current loop control for a grid-tie LCL fuel cell inverter," IEEE Trans. Power Electron., vol. 23, no. 4, pp. 1716-1723, Jul. 2008.

[28] S. Y. Park, C. L. Chen, and J. S. Lai, "A wide-range active and reactive power flow controller for a solid oxide fuel cell power conditioning system," IEEE Trans. Power Electron., vol. 23, no. 6, pp. 2703-2709, Nov. 2008

[29] I. Etxeberria-Otadui, U. Viscarret, M. Caballero, A. Rufer, and S. Bacha, "New optimized PWM VSC control structures converter under unbalanced input voltage transients," IEEE Trans. Ind. Electron., vol. 54, no. 5, pp. 2902-2914, Oct. 2007. 
[30] P. Rodríguez, J. Pou, J. Bergas, J. I. Candela, R. P. Burgos, and D. Boroyevich, "Decoupled double synchronous reference frame PLL for power converters control," IEEE Trans. Power Electron., vol. 22, no. 2, pp. 584-592, Mar. 2007.

[31] F. Wang, J. L. Duarte, and M. A. Hendrix, "Pliant active and reactive power control for grid-interactive converters under unbalanced voltage dips," IEEE Trans. Power Electron., vol. 26, no. 5, pp. 1511-1521, May 2011.

[32] P. Rodriguez, A. V. Timbus, R. Teodorescu, M. Liserre, and F. Blaabjerg, "Flexible active power control of distributed power generation systems during grid faults," IEEE Trans. Ind. Electron., vol. 54, no. 5, pp. $2583-$ 2592, Oct. 2007.

[33] P. Rodriguez, A. V. Timbus, R. Teodorescu, M. Liserre, and F. Blaabjerg, "Reactive power control for improving wind turbine system behavior under grid faults," IEEE Trans. Power Electron., vol. 24, no. 7, pp. 17981801, Jul. 2009.

[34] P. Rodriguez, A. Luna, I. Candela, R. Mujal, R. Teodorescu, and F. Blaabjerg, "Multiresonant frequency-locked loop for grid synchronization of power converters under distorted grid conditions," IEEE Trans. Ind. Electron., vol. 58, no. 1, pp. 127-138, Jan. 2011.

[35] M. Castilla, J. Miret, J. Matas, L. Garcia de Vicuna, and J. M. Guerrero, "Linear current control scheme with series resonant harmonic compensator for single-phase grid-connected photovoltaic inverters," IEEE Trans. Ind. Electron., vol. 55, no. 7, pp. 2724-2733, Jul. 2008.

[36] J. Miret, M. Castilla, J. Matas, J. M. Guerrero, and J. C. Vasquez, "Selective harmonic-compensation control for single-phase active power filter with high harmonic rejection," IEEE Trans. Ind. Electron., vol. 56, no. 8, pp. 3117-3127, Aug. 2009.

[37] A. G. Yepes, F. D. Freijedo, J. Doval-Gandoy, O. Lopez, J. Malvar, and P. Fernandez-Comesana, "Effects of discretization methods on the performance of resonant controllers," IEEE Trans. Power Electron., vol. 25, no. 7, pp. 1692-1712, Jul. 2010.

[38] A. Yazdani and R. Iravani, Voltage-Sourced Converters in Power Systems. Modeling, Control, and Applications. Hoboken, NJ: Wiley, 2009, ch. 7.

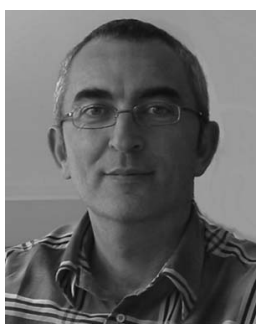

Miguel Castilla received the B.S., M.S., and Ph.D. degrees in telecommunication engineering from the Technical University of Catalonia, Barcelona, Spain, in 1988, 1995, and 1998, respectively.

Since 2002, he has been an Associate Professor with the Department of Electronic Engineering, Technical University of Catalonia, Vilanova i la Geltrú, Spain, where he teaches courses on analog circuits and power electronics. His research interests include the areas of power electronics, nonlinear control, and renewable energy systems.

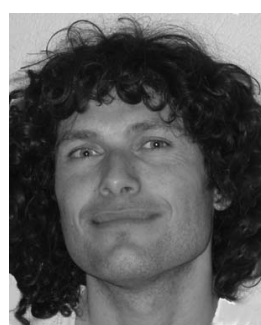

digital control.
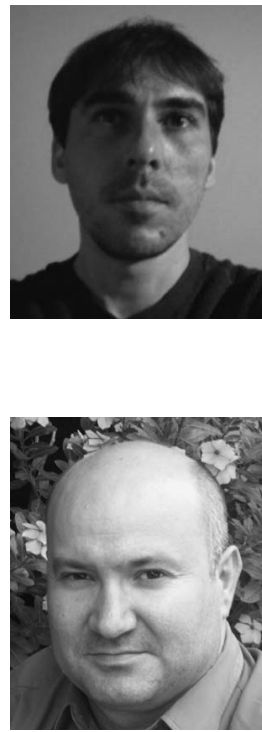

José Matas received the B.S., M.S., and Ph.D. degrees in telecommunications engineering from the Technical University of Catalonia, Barcelona, Spain, in 1988,1996 , and 2003, respectively.

From 1988 to 1990, he was an Engineer with a consumer electronics company. Since 1990, he has been an Associate Professor with the Department of Electronic Engineering, Technical University of Catalonia, Vilanova i la Geltrú, Spain. His research interests include power-factor-correction circuits, active power filters, uninterruptible power systems, distributed power systems, and nonlinear control.

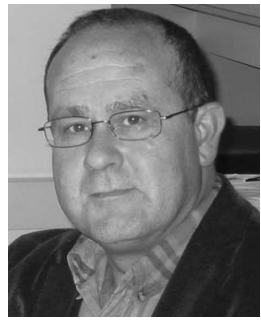

Luis García de Vicuña received the Ingeniero de Telecomunicación and Dr.Ing. degrees from the Technical University of Catalonia, Barcelona, Spain, in 1980 and 1990, respectively, and the Dr.Sci. degree from the Université Paul Sabatier, Toulouse, France, in 1992.

From 1980 to 1982, he was an Engineer with Control Applications Company. He is currently an Associate Professor with the Department of Electronic Engineering, Technical University of Catalonia, Vilanova i la Geltrú, Spain, where he teaches courses on power electronics. His research interests include power electronics modeling, simulation and control, active power filtering, and high-power-factor ac/dc conversion. 